\title{
A New Species of the Genus Dactylochelifer Beier from Shanxi, China (Pseudoscorpiones: Cheliferidae)
}

\author{
Zhi-zhong Gao and Feng Zhang \\ College of Life Sciences, Hebei University, Baoding, Hebei 071002, China \\ Correspondence should be addressed to Feng Zhang, dudu06042001@163.com \\ Received 16 December 2011; Accepted 2 February 2012 \\ Academic Editors: A. Arslan, A. Ramirez-Bautista, and S. Van Nouhuys
}

Copyright ( $) 2012$ Z.-Z. Gao and F. Zhang. This is an open access article distributed under the Creative Commons Attribution License, which permits unrestricted use, distribution, and reproduction in any medium, provided the original work is properly cited.

A new pseudoscorpion species, Dactylochelifer luyaensis sp. nov., belonging to the family Cheliferidae Risso, 1826, is described and illustrated in this paper. The specimens were collected from leaf litter in Shanxi province, China.

\section{Introduction}

Research on the systematics of Chinese pseudoscorpions is poor, and by now, only 73 species (subspecies) have been reported from China [1]. Considering the huge area of China and more than 3400 species known globally [2], obviously, further investigations of pseudoscorpion taxonomy from most areas of China are urgently needed [3].

The genus Dactylochelifer was erected by Beier in 1932 [4], and Chelifer latreillii Leach, 1817 was designated as the type species. This genus is widely distributed in Asia, Europe and North America. It is a large genus in the family Cheliferidae Risso, 1826, and at present includes 44 known species [2], among them only one species has been reported from China, D. gansuensis Redikorzev, 1934 [5].

Luyashan National Nature Reserve is located in the north of LvLiang Mountain Range, Xinzhou city, Shanxi Province. So far, no pseudoscorpions have reported there. Therefore, we went to Luya Mountain for collection in this Summer. While examining the pseudoscorpion specimens collected from leaf litter in Luya Mountain, we found a Dactylochelifer species to be new to science, and named it Dactylochelifer luyaensis sp. nov.

\section{Material and Methods}

The specimens referred to here are preserved in 75\% alcohol and deposited in the Museum of Hebei University (MHBU), Baoding city, China. Microscopical examination was carried out with a Leica M165C stereomicroscope, which was also used for photo taking and the measurements. Drawings were made with the aid of a camera lucida mounted above the eyepiece of a compound microscope. The pattern of description and terminology follow Chamberlin [6] and Harvey [7]. The term "rallum" (for flagellum) is adopted following Judson [8]. Temporary slide mounts were made in glycerol. All measurements are given in $\mathrm{mm}$.

The following abbreviations are used in the paper. Tactile setae: b: basal; sb: subbasal; st: subterminal; t: terminal; ib: interior basal; isb: interior subbasal; ist: interior subterminal; it: interior terminal; eb: exterior basal; esb: exterior sub-basal; est: exterior sub-terminal; et: exterior terminal. Cheliceral setae: gls: galeal seta; es: exterior seta; is: interior seta; sb: sub-basal seta; b: basal seta.

Dactylochelifer luyaensis sp. nov. Figures 1 and 2.

2.1. Type Material. Holotype male (Ps.-MHBU-SX110706), Shanxi Province, Xinzhou City, Luya Mountain, China [ $38^{\circ} 43^{\prime} \mathrm{N}, 111^{\circ} 59^{\prime} \mathrm{E}$ ], alt. $1710 \mathrm{~m}$, July 6, 2011, leg. Zhizhong Gao. Paratypes: 1 male and 4 females, same data as for holotype.

2.1.1. Diagnosis. Small body size and tarsus I were modified; male genital lateral rods weakly fused anteriorly, and each one with an indistinct membranous ring-shaped tube; lateral apodeme well-developed; male galea terminal with 3 


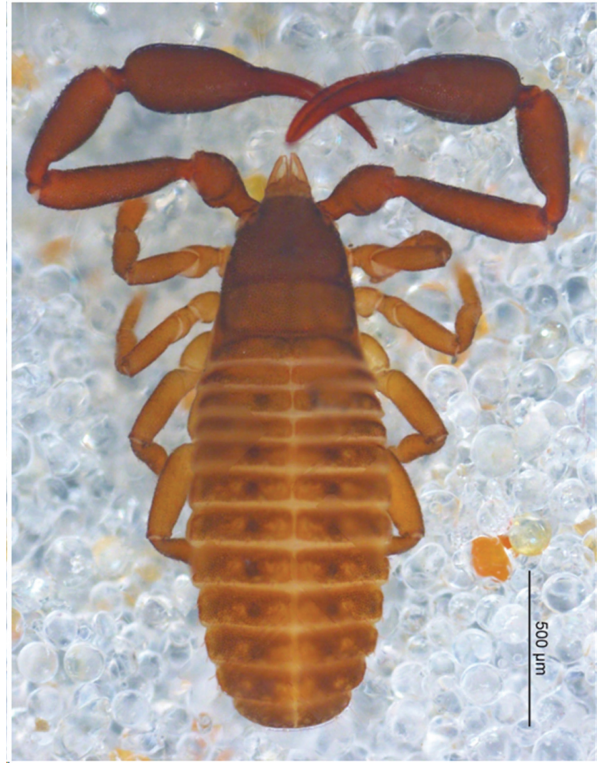

FIGURE 1: Dactylochelifer luyaensis sp. nov.; dorsal view of holotype.

(female 6) short branches; rallum of three blades, anterior two weakly denticulate distally; claws simple.

2.1.2. Etymology. The specific name refers to the type locality.

2.1.3. Description. Color: mostly reddish brown, carapace and pedipalps dark brown, remaining parts (legs, sternites and pleural membranes) light yellowish brown. Most setae denticulate.

Carapace. Surface: evenly and strongly granular. With a pair of well-developed eyes, slightly (1.04 times) longer than broad, both transverse furrows prominent, regularly granular. The median furrow is narrower and deeper than the subbasal one, with a narrow longitudinal shallow groove in metazone. With total of 40-45 setae, including 6 on anterior margin and 8 on posterior margin. All setae are short and deniculoclavate.

Abdomen. All tergites and sternites are divided. Lateral keels absent; weakly granular. Each half tergites with a dark spot close to middle line except tergites I, III, and XI. Tergal chaetotaxy (male): $9: 10: 11: 14: 18: 19: 16: 16: 16: 14: 12$ $(10+2$ long tactile setae): 2 (simple setae). Pleural membrane with transverse groove. All of coxae are smooth; coxa IV is with $c a 34$ setae. Coxal sac taking up about $2 / 3$ coxal length. Atrium is well seen, aperture of coxal sac towards vertical line on prolateral side of coxae IV. Sternal chaetotaxy (IV-XI): $10: 13: 14: 13: 12: 12: 10: 10(8+2$ long tactile setae): 2 (simple and acuminate setae).

Structure of male genitalia of dactylocheliferine form, is as illustrated (Figure 2(13)). Lateral rod is weakly fused anteriorly, each lateral rods with a poorly visible membranous ring-shaped tube attached. Reversible sacs are large; apodeme of eversible well developed with a bigger size as compared to that of other congeners; dorsal apodeme is large; lateral apodeme is very well developed.

Chelicera with poorly-visible scale-shaped sculpture. Five setae in basal part, all of them simple and pointed; with one lyrifissure on the ventral face of palm; both fingers are with a few different-sized teeth in the end. Movable finger with a seta in midway of terminal of finger; serrula exterior with 18 lamellae. Rallum with three blades, anterior two weakly denticulate distally (the first one blade with three spinules; the median one with only one spinule). Galea with three short terminal branches.

Pedipalp with trichobothriotaxy is as illustrated in (Figure 2(4)). Pedipalp slender, all segments with welldeveloped granulation, except for chelal fingers, which are scale-like sculpture; setae are short and prominently clavate; proportions: trochanter 1.41 times as long as broad; femur 3.89 times as long as broad; patella 2.76 times as long as broad; chela with pedicel 3.97 times as long as broad, chela without pedicel 3.72 times as long as broad, hand with pedicel 1.97 times, without pedicel 1.72 times, as long as broad. Movable finger 1.09 times as long as hand with pedicel and 1.24 times without pedicel.

Venom apparatus present in both chelal fingers, venom duct in both fingers slender, extend over trichobothrium $t$ in movable fingers, venom duct short in fixed finger.

Leg I of typical facies, tibia and tarsus with numerous denticulate setae, tactile setae absent, well-visible scale-like sculpture, claws simple and asymmetric (Figure 2(6) and 2(12)); terminal tarsus inflated and modified; proportions: trochanter 1.00 times as long as deep; femur 1.57 times as long as deep; patella 2.23 times as long as deep; tibia 3.00 times as long as deep; tarsus 2.52 times as long as deep. Subterminal tarsal seta simple, arolium shorter than claws.

Leg IV. Surface: weakly and scale-like sculptured; tibia and tarsus with numerous denticulate setae, tactile setae are absent, trochanter 1.78 times as long as deep; femur + patella 3.12 times as long as deep; tibia 3.77 times as long as deep; tarsus 4.50 times as long as deep. Subterminal tarsal seta simple. Claws simple and asymmetric (Figure 2(5)).

Measurements (Length/Breadth, in $\mathrm{mm}$ ). Carapace 0.70/0.67. Pedipalp: trochanter $0.31 / 0.22$; femur $0.70 / 0.18$; patella $0.58 / 0.21$; chela with pedicel $1.15 / 0.29$; length of chela without pedicel 1.08; length of hand with pedicel 0.57 , without pedicel 0.50 ; length of movable finger 0.62 . Leg I: trochanter $0.24 / 0.135$; femur $0.19 / 0.13$; patella $0.43 / 0.17$; tibia $0.415 / 0.11$; tarsus $0.36 / 0.08$. Leg IV: trochanter $0.13 / 0.13$; femur + patella $0.53 / 0.17$; tibia $0.285 / 0.095$; tarsus $0.29 / 0.115$.

Brief Description of Female Paratype. Carapace slightly (1.03 times) longer than broad.

Chaetotaxy: anterior margin with six setae, posterior margin with six setae (total $c a 45$ setae). Tergal chaetotaxy: $12: 17: 18: 19: 22: 22: 21: 22: 21: 18: 15(13+2$ long 

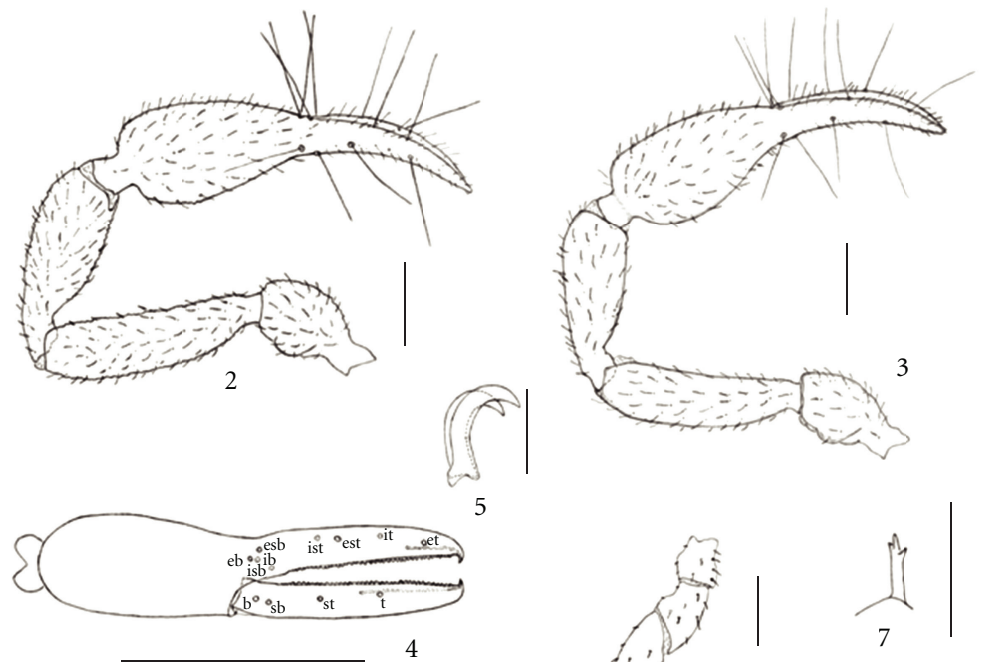

5
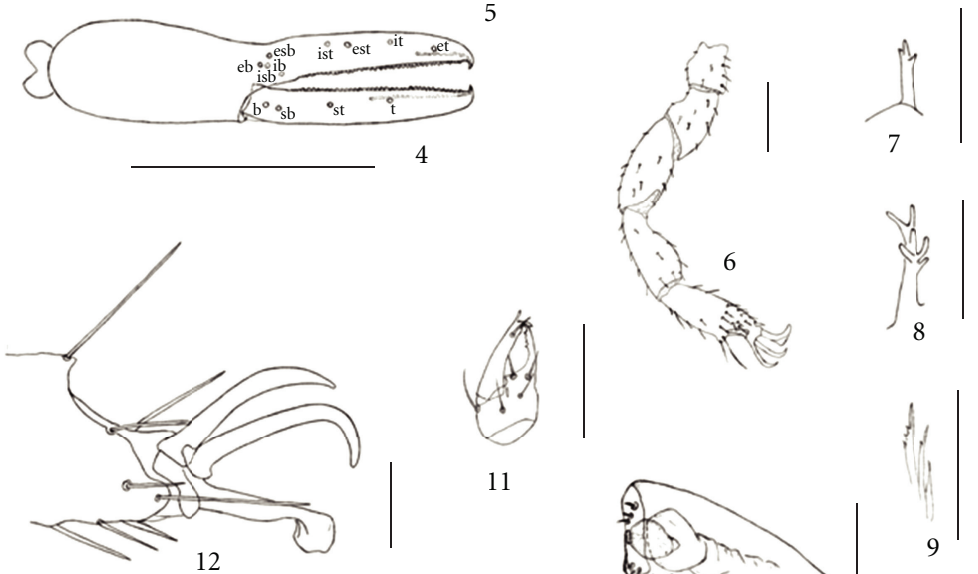

11
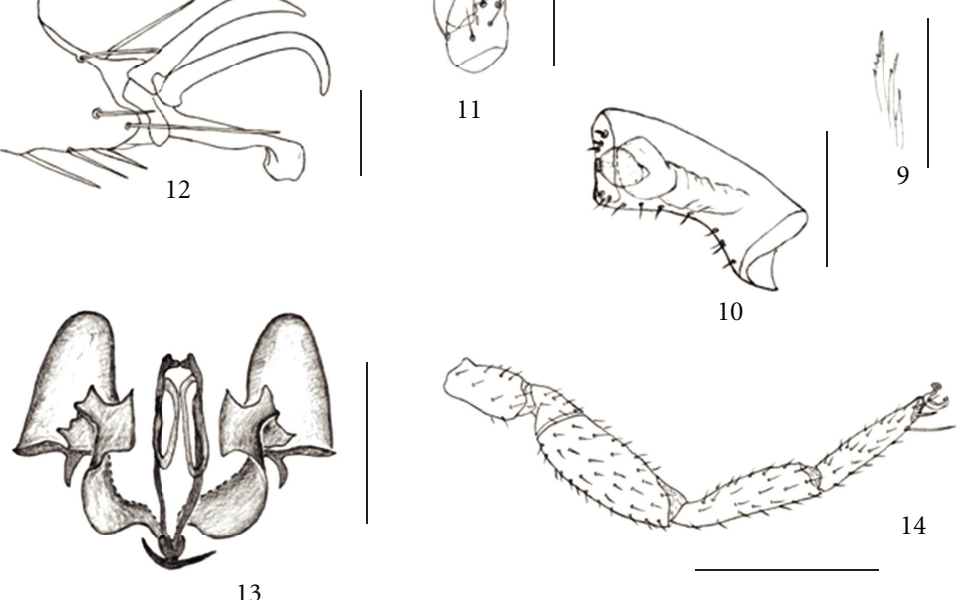

Figure 2: (2-14) Dactylochelifer luyaensis sp. nov., holotype (1,3-6, 8-13) and female paratype (2, 7): (2) left pedipalp, dorsal view; (3) left pedipalp, dorsal view; (4) lateral view of right chelal fingers; showing chaetotary; (5) tarsal claws of leg IV, lateral view; (6) leg I, lateral view; (7) galeadorsal view; 8. galea; dorsal view; (9) rallum; (10) coxae IV, ventral view, showing coxal sac and atrium; (11) chelicera, dorsal view; (12) tarsal claws of leg I, lateral view; (13) genitalia, dorsal view; (14) leg IV, lateral view. Scale bars: $0.5 \mathrm{~mm}(2-4,14) ; 0.2 \mathrm{~mm}(6,10,11 ; 13)$; $0.05 \mathrm{~mm}(5,7-9,12)$.

pseudotactile setae): 2 (short, but incrassate and denticulate terminally). Sternal chaetotaxy: (IV-XI): $11: 14$ : $14: 13: 16: 16: 15: 10(8+2$ long tactile setae $): 2$ short and acuminate setae; one central cribriform plate and two lateral cribriform plate present. Galea with six short terminal branches (Figure 2(8)).

Proportions of pedipalp: trochanter 1.76 times as long as broad; femur 3.95 times as long as broad; patella 3.12 times as long as broad; chela with pedicel 3.88 times as long as broad, without pedicel 3.73 times as long as broad. Hand with pedicel 1.73 times, without pedicel 1.58 times, as long as broad. Movable finger 1.07 times as long as hand with pedicel, and 1.24 times without pedicel.
Measurements (Length/Breadth, in $\mathrm{mm}$ ). Carapace: 0.72/ 0.70 ; Pedipalp: trochanter 0.37/0.21; femur 0.75/0.19; patella 1.06/0.34; chela with pedicel 1.28/0.33; length of chela without pedicel 1.23; length of hand with pedicel 0.57 , without pedicel 0.52 ; length of movable finger 0.67 .

2.1.4. Distribution. Only known from type locality presently.

\section{Remarks}

The genus of Dactylochelifer Beier, 1932, is a taxonomically confused genus [9]. This new species is very similar to 
Dactylochelifer spasskyi Redikorzev, 1949 [10], but can be easily distinguished by smaller body size, by the ratios of carapace and trochanter of pedipalps; It is also different from other congeners by the shape of tarsus I (terminal of tarsus I modified and inflate); in addition, D. luyaensis sp. nov. with one central cribriform plate and two lateral cribriform plate. Differs from $D$. minor $[10]$ and $D$. monticola $[11,12]$ by the ratios of carapace and each segment of pedipalps. Differs from $D$. gobiensis $[10,13]$ by structure of male genitalia (apodeme of eversible sac of more slender), the ratios of carapace and tibia of leg $\mathrm{I}$.

\section{Acknowledgments}

Jun-Fang $\mathrm{Hu}$ kindly helped in paper reviewing the paper. Many thanks are due to four anonymous referees for valuable comments. This paper was supported by the National Natural Science Foundation of China Grant (nos. 31093430, 31071885, and 30970325).

\section{References}

[1] Y. W. Zhao, F. Zhang, Y. Jia, and M. S. Zhu, "A checklist of Pseudoscorpions from China (Arachnida: Pseudoscorpiones)," Acta Arachnologica Sinica, vol. 20, no. 1, pp. 30-41, 2011.

[2] M. S. Harvey, "Pseudoscorpions of the world, version 2.0. western australian museum, Perth," http://www.museum.wa .gov.au/catalogues/pseudoscorpions.

[3] Y. Jia, Y. W. Zhao, and M. S. Zhu, "A new species of the pseudoscorpion genus Bisetocreagris from China (Arachnida: Pseudoscorpiones: Neobisiidae)," Zootaxa, no. 2340, pp. 6568, 2010.

[4] M. Beier, "Pseudoscorpionidea II. Subord. C. Cheliferinea," Tierreich, vol. 58, no. 20, pp. 1-294, 1932.

[5] V. Redikorzev, "Schwedisch-Chinesische wissenschaftliche Expedition nach den nord-westlichen Provinzen Chinas, unter Leitung von Dr. Sven Hedin und Prof. Sü Ping-Chang. Pseudoscorpiones," Arkiv för Zoologi, vol. 27, no. 20, pp. 1-4, 1934.

[6] J. C. Chamberlin, The Arachnid Order Chelonethida, vol. 7, Biological Sciences, Stanford University, 1st edition, 1931.

[7] M. S. Harvey, "The phylogeny and classification of the Pseudoscorpionida (Chelicerata: Arachnida)," Invertebrate Taxonomy, vol. 6, no. 6, pp. 1373-1435, 1992.

[8] M. L. I. Judson, "A new and endangered species of the pseudoscorpion genus Lagynochthonius from a cave in Vietnam, with notes on chelal morphology and the composition of the Tyrannochthoniini (Arachnida, Chelonethi, Chthoniidae)," Zootaxa, no. 1627, pp. 53-68, 2007.

[9] S. Dashdamirov, "A new species of the false-scorpion family Cheliferidae from Thailand, with remarks on Ancistrochelifer and Metachelifer (Arachnida: Pseudoscorpiones)," Zootaxa, no. 1325 , pp. 347-362, 2006.

[10] S. Dashdamirov and W. Schawaller, "Pseudoscorpions from Middle Asia, part 4 (Arachnida: Pseudoscorpiones)," Stuttgarter Beiträge zur Naturkunde, A, vol. 522, pp. 1-24, 1995.

[11] M. Beier, "Pseudoscorpionidea. Contribution à l'étude de la faune d'Afghanistan. 27," Förhandlingar vid Kungliga Fysiografiska Sällskapets i Lund, vol. 30, pp. 41-45, 1960.
[12] M. Beier, "Pseudoscorpionidea II. Contribution à l'étude de la faune d'Afghanistan. 56," Förhandlingar vid Kungliga Fysiografiska Sällskapets i Lund, vol. 31, pp. 1-4, 1961.

[13] M. Beier, "Pseudoscorpionidea. Ergebnisse der zoologischen Forschungen von Dr. K. Kaszab in der Mongolei," Reichenbachia, vol. 11, pp. 283-286, 1969. 

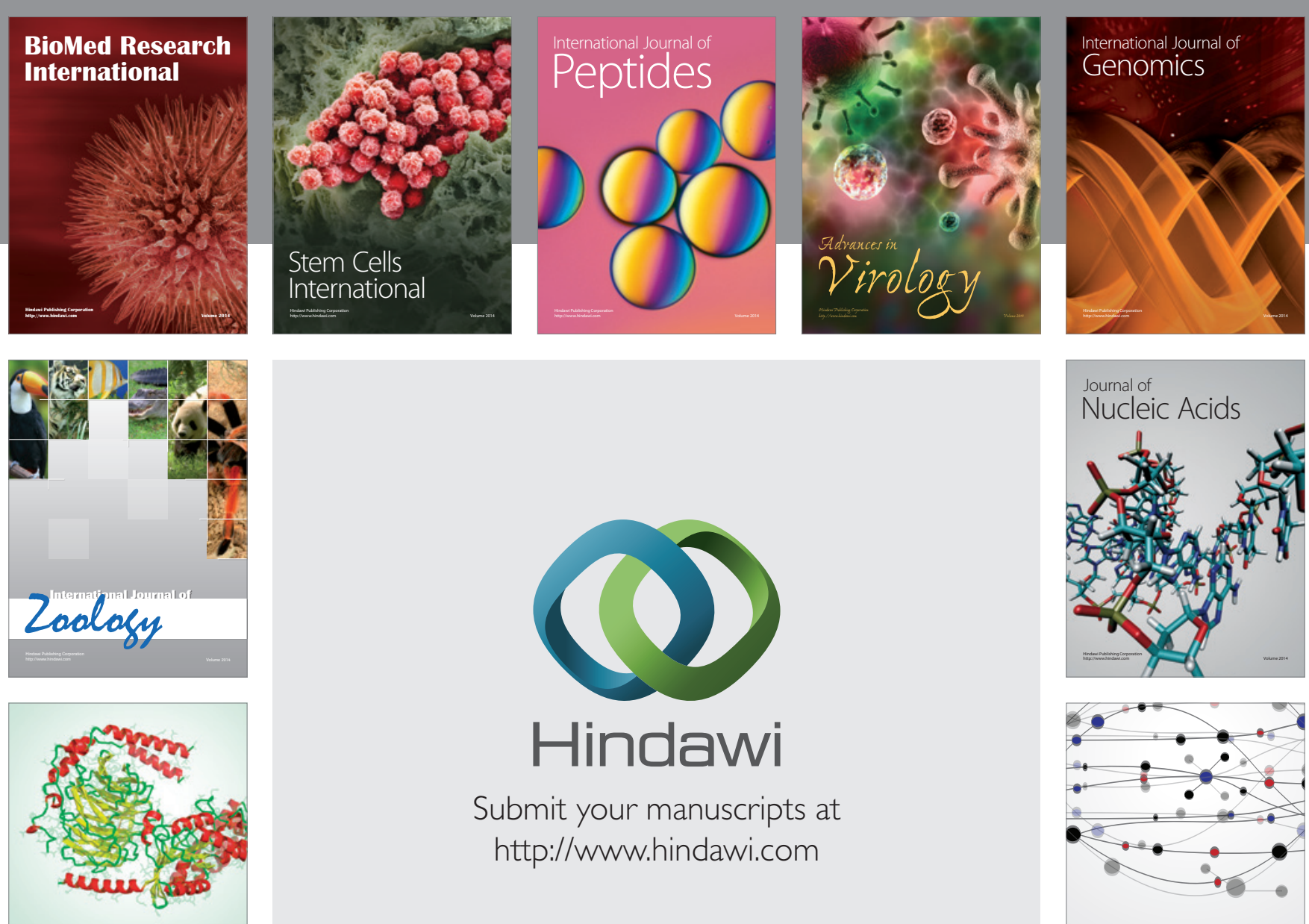

Submit your manuscripts at

http://www.hindawi.com

Signal ${ }^{\text {Jumal }}$ Transduction
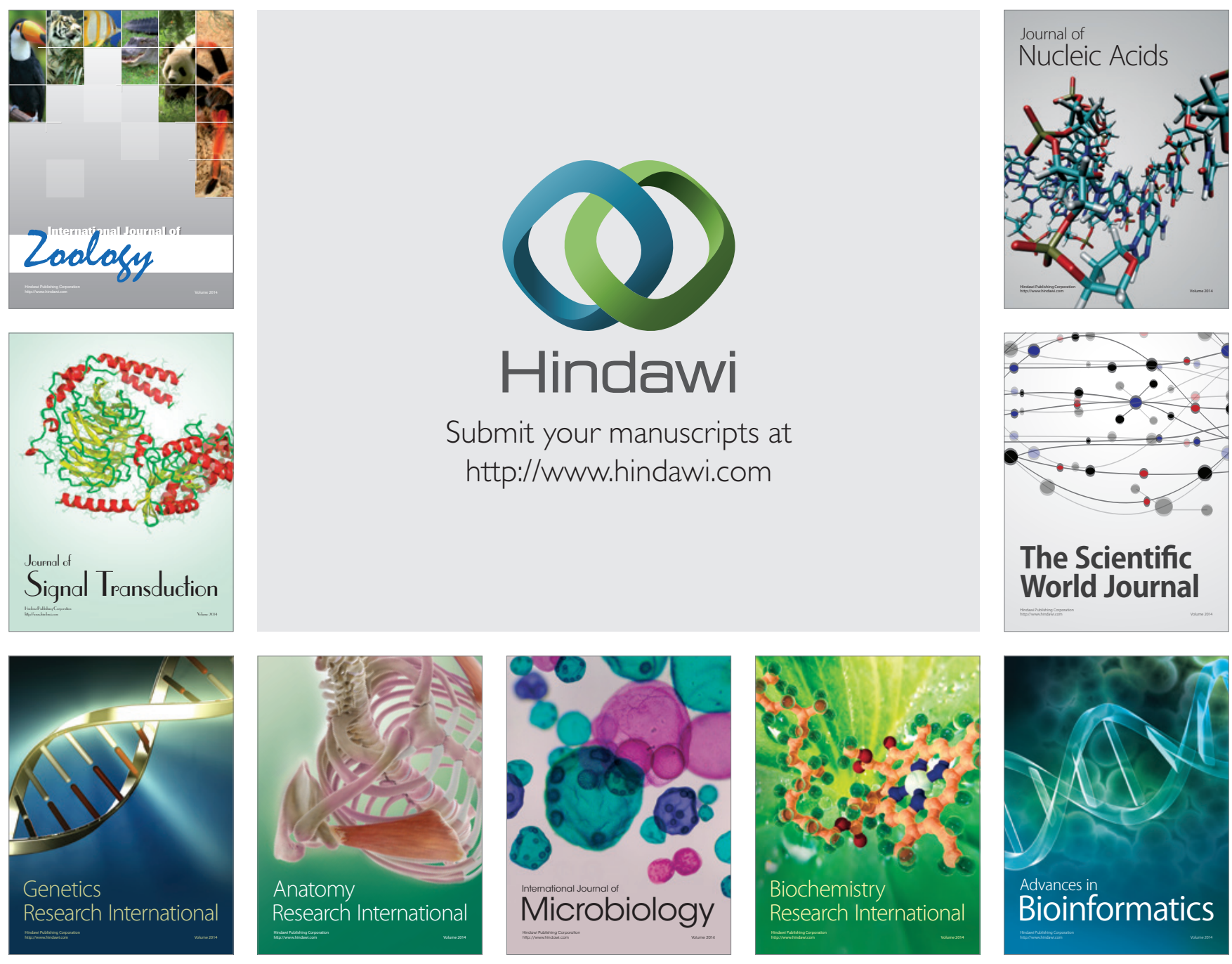

The Scientific World Journal
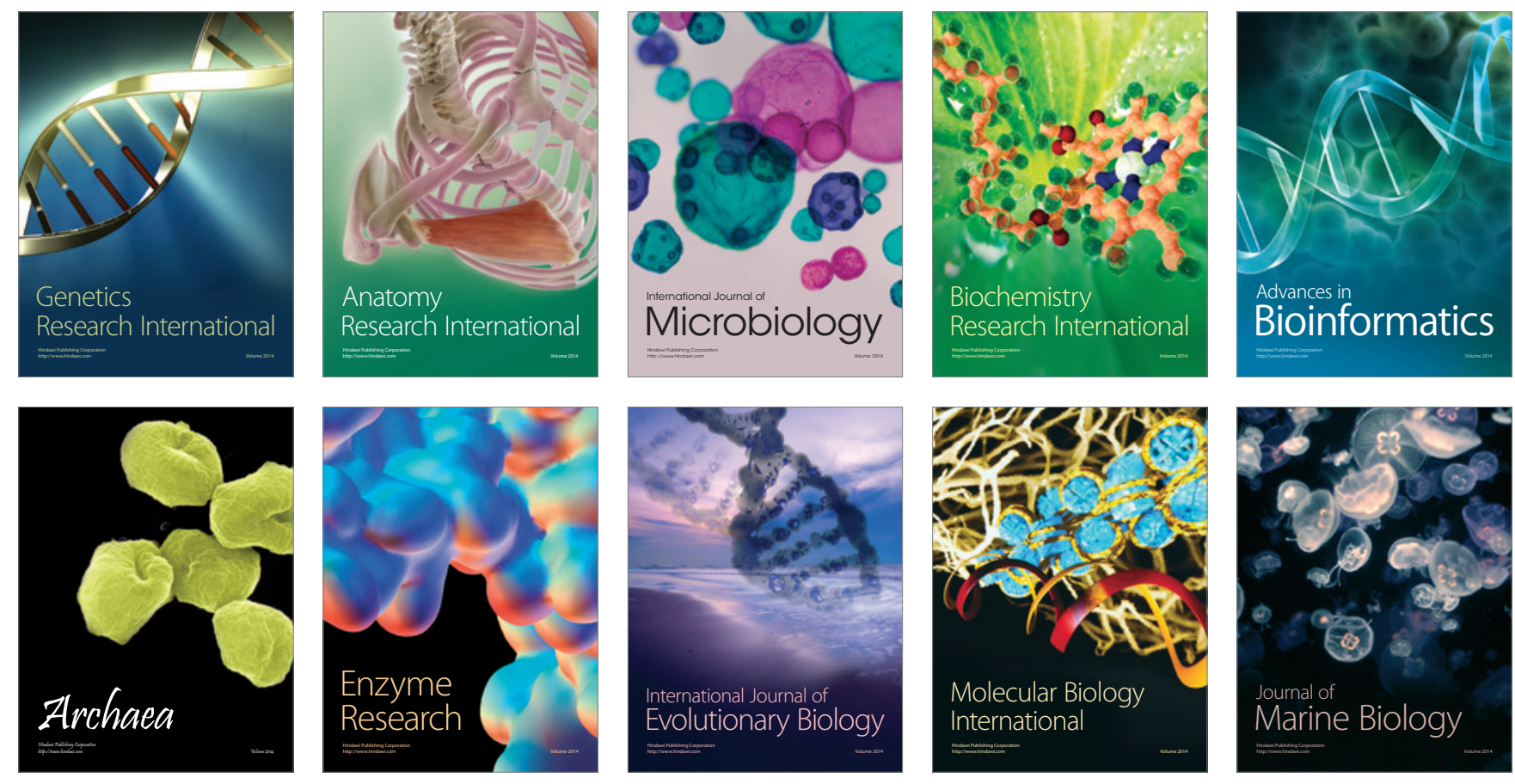